\title{
Individual risk attitudes: measurement, determinants and behavioral consequences
}

Citation for published version (APA):

Dohmen, T. J., Falk, A., Huffman, D., Sunde, U., Schupp, J., \& Wagner, G. G. (2009). Individual risk attitudes: measurement, determinants and behavioral consequences. METEOR, Maastricht University School of Business and Economics. METEOR Research Memorandum No. 039 https://doi.org/10.26481/umamet.2009039

Document status and date:

Published: 01/01/2009

DOI:

10.26481/umamet.2009039

Document Version:

Publisher's PDF, also known as Version of record

\section{Please check the document version of this publication:}

- A submitted manuscript is the version of the article upon submission and before peer-review. There can be important differences between the submitted version and the official published version of record.

People interested in the research are advised to contact the author for the final version of the publication, or visit the DOI to the publisher's website.

- The final author version and the galley proof are versions of the publication after peer review.

- The final published version features the final layout of the paper including the volume, issue and page numbers.

Link to publication

\footnotetext{
General rights rights.

- You may freely distribute the URL identifying the publication in the public portal. please follow below link for the End User Agreement:

www.umlib.nl/taverne-license

Take down policy

If you believe that this document breaches copyright please contact us at:

repository@maastrichtuniversity.nl

providing details and we will investigate your claim.
}

Copyright and moral rights for the publications made accessible in the public portal are retained by the authors and/or other copyright owners and it is a condition of accessing publications that users recognise and abide by the legal requirements associated with these

- Users may download and print one copy of any publication from the public portal for the purpose of private study or research.

- You may not further distribute the material or use it for any profit-making activity or commercial gain

If the publication is distributed under the terms of Article $25 \mathrm{fa}$ of the Dutch Copyright Act, indicated by the "Taverne" license above, 
Thomas Dohmen, Armin Falk, David Huffman, Uwe Sunde, J ürgen Schupp, Gert G. Wagner

I ndividual Risk Attitudes: Measurement, Determinants and Behavioral Consequences

$\mathrm{RM} / 09 / 039$

\section{METEOR}

Maastricht University School of Business and Economics 


\title{
INDIVIDUAL Risk ATtitudes: \\ Measurement, Determinants AND Behavioral CONSEQUENCES
}

\author{
Thomas Dohmen \\ ROA, Maastricht University, IZA, and DIW \\ Armin Falk \\ University of Bonn, IZA, DIW, and CEPR \\ David Huffman \\ Swarthmore College and IZA \\ Uwe Sunde \\ University of St. Gallen, IZA, DIW, and CEPR
}

Jürgen Schupp

DIW, Berlin, and IZA

Gert G. Wagner

DIW, Berlin, Berlin University of Technology, Cornell University, and IZA

\begin{abstract}
This paper studies risk attitudes using a large representative survey and a complementary experiment conducted with a representative subject pool in subjects' homes. Using a question asking people about their willingness to take risks "in general", we find that gender, age, height, and parental background have an economically significant impact on willingness to take risks. The experiment confirms the behavioral validity of this measure, using paid lottery choices. Turning to other questions about risk attitudes in specific contexts, we find similar results on the determinants of risk attitudes, and also shed light on the deeper question of stability of risk attitudes across contexts. We conduct a horse race of the ability of different measures to explain risky behaviors such as holdings stocks, occupational choice, and smoking. The question about risk-taking in general generates the best all-around predictor of risky behavior. (JEL codes: D0, D1 D80, D81, C91, C93, J16, J24, I1)
\end{abstract}


Risk and uncertainty play a role in almost every important economic decision. As a consequence, understanding individual attitudes towards risk is intimately linked to the goal of understanding and predicting economic behavior. A growing literature has made progress on developing empirical measures of individual risk attitudes, with the aim of capturing this important component of individual heterogeneity (see, e.g., Bruhin et al., 2007), but many questions remain unresolved.

One important open question concerns the determinants of individual differences in risk attitudes. Previous studies have measured risk attitudes using survey questions, and found mixed evidence on determinants, for example gender. ${ }^{1}$ A second open question, however, is whether survey questions are really a good method for measuring risk attitudes. Because survey questions are not incentive compatible, economists are skeptical about whether self-reported personal attitudes and traits are behaviorally meaningful. Various factors, including self-serving biases, inattention, and strategic motives could cause respondents to distort their reported risk attitudes (for a discussion, see Camerer and Hogarth, 1999). Experimental studies, which measure risk-taking behavior with real money at stake, on the other hand, offer an incentive compatible measure of risk attitudes. $^{2}$ However, a drawback of this technique is that it is costly and difficult to perform with a large, representative sample, preventing studies at a large scale. ${ }^{3}$ A related, but largely unexplored issue is how context and question format matter for eliciting risk attitudes. Survey studies have almost always used a question framed in one relatively specific context: a (hypothetical) decision regarding a financial lottery. It is conceivable, however, that alternative survey instruments, which are easier to understand than fairly complicated hypothetical lotteries, can deliver similarly reliable information on individual risk attitudes.

In this paper we address these open questions by investigating responses to a survey

${ }^{1}$ See, for example, Barsky et al. (1997), Guiso and Paiella (2001) 2005, Donkers et al. (2001), Guiso et al. (2002), and Diaz-Serrano and O'Neill (2004).

2 See, e.g., Binswanger (1980), Schubert et al. (1999), Holt and Laury (2002), Barr and Packard (2002), Eckel et al. (2005), Eckel and Grossman (2007) and Choi et al. (2007).

${ }^{3}$ A notable exception in the literature is the work by Harrison et al. (2007) who conduct risk experiments among 253 Danes that were carefully sampled to reflect a representative subject pool of the Danish population. 
item that asks individuals about a judgment of their own willingness to take risks. This self-assessment complements traditional lottery-type elicitation of risk attitudes, and we compare the responses to behavior in paid real-stakes lotteries. The results shed light on the determinants of risk attitudes in a representative sample, as well as the behavioral validity of the survey instrument. The paper also compares the responses with multiple alternative questions about risk attitudes that using different contexts and approaches, which were asked in the same survey. This allows us to assess the robustness of results such as a gender difference in risk attitudes to the use of different types of risk measures, and it is also useful for determining the best way to reliably capture an individual's risk taking tendencies in different contexts.

The analysis makes use of different sources of data. The first data source is the German Socio-Economic Panel (SOEP), which measures the risk attitudes of more than 22,000 individuals. The sample is carefully constructed to be representative of the adult population living in Germany. The representativeness and statistical power afforded by the survey allow us to study the determinants of risk attitudes in detail. The survey is also attractive in that it incorporates a variety of different approaches to measuring risk attitudes. For example, one question directly asks individual's to make a global assessment of their willingness to take risks: "How willing are you to take risks, in general?" Respondents rate their willingness on a scale from 0 to 10 . We call this simple, ordinal measure the "general risk question". Initially, we use this measure to study heterogeneity and determinants of risk attitudes in the population. Our first set of results includes evidence of substantial heterogeneity in risk attitudes, and strong evidence that gender, age, height, and parental background play an important role in explaining individual differences in risk attitudes.

A crucial concern is whether survey questions can be meaningfully interpreted in terms of actual risk-taking behavior. In order to address this question, we use a second data source: a field experiment conducted with an additional representative sample of 450 subjects, drawn from the adult population in Germany using exactly the same methodology as for the SOEP. Participants in our experiment answer the same general 
risk question asked to participants in the SOEP. The respondents also make choices in a real-stakes lottery experiment. We find that responses to the general risk question are a reliable predictor of actual risky behavior, even controlling for a large number of observables. This lends confidence to the behavioral validity of our results for the larger survey data set, based on the validated survey measure. ${ }^{4}$ More generally, the findings document that a simple, qualitative survey measure can generate a meaningful measure of risk attitudes, which maps into actual choices in lotteries with real monetary consequences. This is important because it suggests that surveys can collect information on risk attitudes using instruments that are easy to use and relatively cheap to administer, and yet deliver a behaviorally valid measure of risk attitudes. While we are aware that hypothetical questions are not a perfect substitute for elicitation of risk preferences using paid lottery experiments, we see considerable value added in documenting the relationship in responses with experimental elicitation instruments, underscoring the usefulness (and relative advantage) of these measures for elicitation of risk attitudes in large-scale surveys.

With the behavioral validity of the general risk question in terms of predicting behavior in the experiment in mind, we return to an analysis of the larger SOEP data set, and exploit additional questions about risk attitudes. In particular, the survey includes five additional questions that use the same scale as the general risk question, but ask about risk taking in specific contexts: car driving, financial matters, sports and leisure, health, and career. We find that the results on determinants are robust to using these alternative risk measures, e.g., females are less willing to take risks in every context. We also assess the stability of risk attitudes across contexts. In economics it is common to think of a single trait as governing risk-taking in all contexts, whereas in psychology there is more controversy on this point. ${ }^{5}$ Our results suggest that risk attitudes are strongly but not perfectly correlated across contexts. This suggests the presence of a common

\footnotetext{
${ }^{4}$ In focusing on the consistency of survey responses to a new survey instrument with risk behavior in lotteries, our investigation about the behavioral validity complements earlier work on hypothetical bias, see, e.g., Holt and Laury (2002) for a central contribution in the context of risk attitudes.

${ }^{5}$ See, e.g., Slovic (1972a).
} 
underlying risk trait, but also points to some value-added from asking context-specific questions.

Finally, the survey includes self-reported information on several important risky behaviors: holding stocks, being self-employed, participating in sports, and smoking. This allows us to compare the relative ability of the different measures of risk attitudes to explain these risky behaviors. We find that all measures are significantly related to several behaviors, providing further evidence on their behavioral validity. The best all-around explanatory variable, however, is the general risk question, which predicts all behaviors. On the other hand, although less successful across contexts, the single best risk measure in any given context is the measure incorporating the corresponding specific context. For example, the best predictor of smoking is the question about willingness to take risks in health matters, rather than the general risk question or questions incorporating different contexts. These findings indicate that asking for a global assessment of willingness to take risks reflects a useful all-around measure of risk attitudes. Questions focused on specific contexts do less well as all-around predictors, but provide strong measures within their particular domain of risky behavior.

The organization of the paper is as follows. Section 1 describes the SOEP and the risk measures that we use. Section 2 investigates heterogeneity and determinants of risk attitudes using the general risk question. Section 3 presents results from the complementary field experiment. Section 4 assesses the stability of risk attitudes across different contexts. Section 5 compares the predictive power of the different risk measures and Section 6 discusses the implications of our results.

\section{Data Description}

The SOEP is a representative panel survey of the resident adult population of Germany (for a detailed description, see Wagner et al., 1993, and Schupp and Wagner, 2002). The initial wave of the survey was conducted in 1984. The SOEP surveys the head of each household in the sample, but also gives the full survey to all other household 
members over the age of 17. Respondents are asked for a wide range of personal and household information, and for their attitudes on assorted topics, including political and social issues. Our analysis uses the 2004 wave, which includes 22,019 individuals in 11,803 different households.

Much of our analysis focuses on the general risk question in the SOEP, which directly asks respondents to give a global assessment of their willingness to take risks. The exact wording of which (translated from German) is as follows: "How do you see yourself: are you generally a person who is fully prepared to take risks or do you try to avoid taking risks? Please tick a box on the scale, where the value 0 means: "not at all willing to take risks' and the value 10 means: 'very willing to take risks'." 6 Notably, the measure is qualitative and does not involve an explicit lottery. Rather, it relies on the subject to give an assessment of willingness to take risks in general, across the various types of lotteries (some of which may be non-financial) that could be faced in decision making. This approach is potentially attractive, for the purpose of eliciting a reliable all-around measure of risk attitudes across contexts, something which we evaluate empirically in our analysis. Because there are no explicit stakes or probabilities in the question, there is the potential that factors other than risk preference could lead to variation in responses across individuals. Specifically, subjective beliefs about the riskiness of the decision environment could affect someone's stated willingness to take risks. For this reason, it is informative whether the measure explains risky behavior in our field experiment, where choices involve paid lotteries with explicit stakes and probabilities, and thus subjective beliefs about risk are held constant. A positive result from the validation exercise would confirm that the measure does not just reflect subjective beliefs. Five additional measures use the same wording as the general risk question, and the same scale, but ask about willingness to take risks in a specific context: car driving, financial matters, leisure and sports, career, and health.

${ }^{6}$ In German, the wording of the question is: "Wie schätzen Sie sich persönlich ein: Sind Sie im allgemeinen ein risikobereiter Mensch oder versuchen Sie, Risiken zu vermeiden? Bitte kreuzen Sie ein Kästchen auf der Skala an, wobei der Wert 0 bedeutet: "gar nicht risikobereit" und der Wert 10: "Sehr risikobereit". Mit den Werten dazwischen können Sie Ihre Einschätzung abstufen." German versions of all risk questions are available online, at www.diw.de/gsoep/. 
Not every respondent answered all questions, but non-response rates are fairly low. The number of non-responses out of 22,019 for each of the six question is as follows: 72 for general, 1,349 for car driving, 262 for financial matters, 379 for sports and leisure, 2,051 for career, and 85 for health.

Our analysis also incorporates a field experiment, in which the subjects are a random sample of the population, drawn using exactly the same procedure as for the SOEP (sampling is done using the targeted random walk method; see Thompson, 2006). ${ }^{7}$ The experiment involved a separate subject pool, rather than involving participants from the SOEP panel. In the experiment, subjects answered a questionnaire similar to the SOEP, which included the general risk question. Subjects then took part in a lottery experiment. We describe the experiment in detail in the validation section below. The questionnaire and experiment were conducted by experienced interviewers who were recruited out of the pool of interviewers who conduct the regular SOEP survey. Interviews took place face-toface at the subjects' homes. Both answers to the questionnaire and the decisions in the lottery experiment were typed into a computer by a professional interviewer (Computer Assisted Personal Interview (CAPI)). The study was run between June 9th and July 4th, 2005, and a total of 450 participants took part.

\section{Willingness to Take Risks in General: Heterogene- ity and Determinants}

This section presents the distribution of willingness to take risks in the population, as measured by the general risk question, and then turns to the investigation of possible determinants of individual differences in risk attitudes.

The Figure 1 shows the distribution of general risk attitudes in our representative sample. Each bar indicates the fraction of individuals choosing a given number on the

\footnotetext{
${ }^{7}$ For each of 179 randomly chosen primary sampling units (voting districts), one trained interviewer was given a randomly chosen starting address. Starting at that specific local address, the interviewer contacted every third household and interviewed one adult person aged 16 or older per household.
} 
eleven point risk scale. The figure reveals substantial heterogeneity in risk attitudes across the population: the modal response is 5 , but risk attitudes vary widely over the entire scale, with mass distributed over the entire support. A relatively small fraction of respondents chooses a value of 10, indicating that they are very willing to take risks, while a somewhat larger mass, roughly 7 percent of all individuals, choose 0 , indicating that they are not at all willing to take risks.

Next, we investigate whether some of the heterogeneity in risk attitudes is systematic, thus leading to differences in economic decisions across different types of individuals. We focus on the impact of four personal characteristics: gender, age, height, and parental background. These characteristics are plausibly exogenous with respect to individual risk attitudes and behavior, and thus allow us to give a causal interpretation to correlations and regression results. ${ }^{8}$ There are also important implications if these characteristics have an impact on risk attitudes. For example, a gender difference in risk attitudes could be part of the explanation for gender differences in social behavior and economic outcomes.

A first look at the data shows that the proportion of individuals who are relatively unwilling to take risks, i.e., choose low values on the scale, is higher for women and increases strongly with age. ${ }^{9}$ Likewise, family background in terms of parental education appears to play a role in determining risk attitudes, indicating a positive correlation between parental education and willingness to take risks. Finally, height appears to be a relevant determinant of risk attitudes, with taller individuals being willing to take risks for both genders.

To determine the joint role of these four exogenous characteristics simultaneously, we estimate regressions where the dependent variable is an individual's response to the general risk question. Because the dependent variable is measured in intervals, on an 11-

\footnotetext{
${ }^{8}$ Note, however, the caveat that age could potentially be endogenous, for example if people who are less willing to take risks live longer.

${ }^{9}$ Willingness to take risks appears to decrease steadily with age for men, whereas for women willingness to take risks decreases more rapidly from the late teens to age thirty, and then remains flat, until it begins to decrease again from the mid-fifties onwards. A graphical illustration of this finding as well as the other unconditional correlations can be found in the discussion paper version of this paper, see Dohmen et al. (2005). Interestingly, this pattern in early life for women is not solely driven by the occurrence of childbirth; the pattern is similar for the sub-sample of women who never have a child.
} 
point scale, throughout the analysis we use interval regression techniques. ${ }^{10}$ All estimation results report robust standard errors, corrected for possible correlation of the error term across individuals from the same household. The only sample restriction is the omission of individuals with missing values for the variables in a given regression.

Table 1 summarizes our initial regressions. The baseline specification, presented in column (1), uses gender, age and height as explanatory variables. The resulting coefficient estimates show that the unconditional results remain robust. Women are significantly less willing to take risks in general. Willingness to take risks also decreases significantly with age. Unreported regressions including age in splines, with knots at 30 and 60 years, reveal that the age effect is particularly strong for young and old ages. The inclusion of splines leaves the estimates of the other coefficients virtually unchanged. ${ }^{11}$ Taller people are more willing to take risks. All of these effects are individually and jointly significant at the 1-percent level. ${ }^{12}$ Column (2) repeats the same estimation adding indicator variables for having a mother or father who have completed the Abitur as exogenous characteristic from the individual point of view. ${ }^{13}$ Having a mother or father with completed Abitur significantly increases willingness to take risks. Again, this effect is individually and jointly significant at any conventional level.

10 Rather than interpreting responses as continuous variable, this approach treats each value of the dependent variable as a left and right censored observation coming from an interval with known bounds and accounts for censoring. The interval regression procedure maximizes a likelihood function that is a natural generalization of a Tobit. Error terms are assumed to be normally distributed. Reported coefficients reflect marginal effects. We also estimated all regressions using Ordered Probit models, OLS regressions, or using a binary Probit classification with a measure of risk attitudes as the dependent variable, which takes a value of 1 for individuals who report a value above 5 on the general risk scale and 0 otherwise. In all instances we found the same qualitative results and similarly significant and robust coefficients. Results based on any of these alternative estimation methods are available upon request.

11 Results for spline regressions are available upon request.

12 Results from OLS regressions deliver almost identical results. The corresponding R-square measure is 0.12. A likelihood-ratio test reveals that adding interaction terms between all independent variables improves the fit. The coefficients of interest in the unrestricted specification, however, are very similar to those from the restricted model, both qualitatively and quantitatively. We prefer the model reported in column (1) of Table 1 for ease of presentation and interpretation.

13 There are two types of high school in Germany, vocational and university-track. The Abitur is an exam that is completed at the end of university-track high schools and qualifies an individual to attend university. Thus the Abitur is an indicator of relatively high academic achievement, especially for older cohorts. Hence, we take whether or not a parent passed the Abitur, an exam that comes at the end of university-track high school in Germany and is a prerequisite for attending university, as a proxy for highly-educated parents. In our sample, roughly 7 percent of mothers and 13 percent of fathers have completed the Abitur. 
Columns (3) to (6) check the robustness of our findings by including other control variables. Two potentially important controls are income and wealth. High income or wealth levels may increase the willingness to take risks because they cushion the impact of bad realizations. A potential problem with adding these variables to the regression is that they may be endogenous, e.g., a greater willingness to take risks could lead to high wealth levels. Wealth and income are sufficiently important economic variables, however, that it is arguably important to know how they affect the baseline results when they are included in the regression. ${ }^{14}$ Column (6) is the fullest specification, controlling for household wealth and income simultaneously, and also adding a large number of other personal and household characteristics. These additional characteristics, which are all potentially endogenous, include among others: marital status, socialization in East or West Germany, nationality, employment status (white collar, blue collar, private or public sector, selfemployed, non-participating), education, subjective health status, and religion. ${ }^{15}$ For the sake of brevity, Table 1 does not report coefficient estimates for all of the additional controls. The precise specification and all coefficient estimates are shown in Table A.1 in the Appendix.

A comparison of the results in columns (3) to (6) to results in columns (1) and (2) shows that the coefficient estimates for gender, age, and height are virtually unchanged, and remain equally statistically significant when we include the additional income and wealth controls. Women are less willing to take risks than men. ${ }^{16}$ Increasing age leads to decreasing willingness to take risks, and increasing height leads to a greater willingness to take risks. Having a mother who completed the Abitur, and somewhat less strongly having a father who completed the Abitur, increases an individual's willingness to take risks.

\footnotetext{
${ }^{14}$ For details on the construction of income and wealth measures in the SOEP, see the notes for Table 1.

${ }^{15}$ Again, OLS results are almost identical, with an R-squared of 0.17 for a specification corresponding to that reported in column (6).

${ }^{16}$ We also studied the gender difference in risk attitudes using Oaxaca-Blinder decomposition techniques (see Blinder, 1973, and Oaxaca, 1973), which allow the separation of differences in observable characteristics from differences in regression coefficients. We found that more than 60 percent of the gender gap is explained by differences in coefficients rather than characteristics, regardless of the specification or the reference group chosen.
} 
Importantly, the effects of gender, age, height, and parental education on willingness to take risks are also quantitatively significant. For example, given that one standard deviation for the general risk question is about 2.4, the gender effect corresponds to a substantial decrease in willingness to take risks, about one quarter of a standard deviation. In the last section of the paper, where we relate risk attitudes to different important risky behaviors, we return to a discussion of the economic significance of the determinants identified in this section.

Although causal interpretations are inadvisable, it is interesting that the correlation between wealth or income and risk attitudes goes in the predicted direction, i.e., these correlations are invariably positive and significant, indicating that wealthier individuals are more willing to take risks. For example, the unconditional correlation between general risk attitudes and log household income is 0.20 , and the correlation with log household wealth is 0.06 , significant at any conventional level. The positive relationship between income or wealth and willingness to take risks remains when we control for other observables (see coefficient estimates in column (1) of Table A.1 in the Appendix). There are also a number of other noteworthy correlations, reported in Table A.1. For example, being widowed, having a bad subjective health status, and being out of the labor force are all significantly negatively correlated with willingness to take risks. Willingness to take risks decreases with number of children. People with high life satisfaction are more willing to take risks.

\section{Experimental Validation of Survey Measures}

The previous section identified several exogenous factors that determine individual risk attitudes. Importantly, these conclusions were drawn from a large and representative survey. The scope of the results is therefore considerably larger than that of economic experiments, which typically use a relatively small and often selective sample. A serious concern with the use of hypothetical questions, however, is that responses are not incentive compatible. As a result it is unclear to what extent the general risk question is a reliable 
indicator for actual risk taking behavior.

In light of this discussion, the researcher who is interested in the measurement of risk attitudes faces a dilemma. Running an incentive compatible experiment with, say, 22,000 subjects is hardly a feasible option, given the substantial associated administrative and financial costs. Conducting experiments with affordable but relatively small sample sizes, on the other hand, leaves the researcher with limited statistical power. In this paper our solution is to run a large survey including risk measures but also a complementary field experiment that tests the behavioral validity of the survey measures. This procedure offers the advantages of both statistical power and confidence in the reliability of the survey questions. ${ }^{17}$ In order to validate our survey risk measure, we ran a lottery experiment based on a representative sample of adult individuals living in Germany, and had the same individuals answer a detailed questionnaire. Of course, it would also be possible to validate the measure in a lab experiment with undergraduates, a relatively easy and potentially less expensive option. Strictly speaking, however, this would only allow validation of the survey questions for this special subgroup of the total population, which is why we decided on our alternative design. ${ }^{18}$

In our experimental study, subjects first went through a detailed questionnaire, similar to the standard SOEP questionnaire. As part of the questionnaire we asked the general risk question analyzed in the previous section. After completion of the questionnaire, participants took part in a paid lottery experiment. ${ }^{19}$ In the experiment participants were shown a table with 20 rows. In each row they had to decide whether they preferred a safe

17 There is a parallel with the literature on contingent valuation, which has used experiments to explore the validity of survey questions about preferences for environmental amenities or other goods. See, e.g., Blackburn, et al. (1994), and Champ and Bishop (2001), among others.

18 Several recent studies have pointed out that student samples are not representative for a broad population, and have therefore run experiments on representative samples, see, e.g., Bellemare and Kröger (2007) in the context of trust, and Harrison et al. (2007) in the context of risk experiments.

19 The general risk question was asked as question 19 in the questionnaire, and the risk experiment was conducted after subjects had answered question 104. Thus, a considerable amount of time (more than 20 minutes) passed between answering the general risk question and making choices in the lottery experiment, during which participants answered 85 different questions, many with several sub-items. This time delay, together with the fact that the lottery choices involved considerable financial incentives, helps eliminate any spurious relationship between the general risk question and lottery choices, arising due to a psychological desire to make choices that are consistent with previous survey responses. In fact, see Saris and van Meurs (1990) and Saris (2003) for evidence that a time delay of 20 minutes between measures suffices to eliminate memory effects. 
option or playing a lottery. In the lottery they could win either 300 Euros or 0 Euros with 50 percent probability (1 Euro $\sim \$$ US 1.2 at the time of the experiment). In each row the lottery was exactly the same but the safe option increased from row to row. In the first row the safe option was 0 Euros, in the second it was 10 Euros, and so on up to 190 Euros in row 20. After a participant had made a decision for each row, it was randomly determined which row became relevant for the participant's payoff. Depending on the subject's choice in that row, the subject's payoff would either be the safe payment from that row, or the outcome of the lottery. This procedure guarantees that each decision was incentive compatible. Once a respondent preferred the safe option to playing the lottery, the interviewer asked whether the respondent would also prefer the even higher safe payments to playing the lottery, and all subjects responded in the affirmative. The switching point is informative about a subject's risk attitude. Since the expected value of the lottery is 150 Euros, weakly risk averse subjects should start to prefer the safe option over the lottery for save payments that are less than 150 Euros. They should also prefer larger safe payments to the lottery. Only risk loving subjects should opt for the lottery when the offered safe option is 160, 170, 180, or 190 Euros. The increments in the safe payment, and maximum value of 190, were chosen to allow a relatively fine grid for categorizing different degrees of risk aversion, risk neutrality, or risk lovingness, while also keeping the length of the choice table manageable. For example, safe payments higher than 190 would either require lengthening the table, or using a coarser grid. As very few individuals are typically extremely risk loving, a maximum of 190 was chosen. As discussed below, the fact that the table is bounded at 190 is inconsequential for our results.

In order to ensure incentive compatibility, subjects were informed that after the experiment a random device would determine whether they would be paid according to their decision, and that the chance of winning was $1 / 7$ (see Laury, 2006, for evidence that this delivers very similar results to the alternative procedure of paying each subject with probability 1). At the end of the experiment subjects learnt the outcome of the chance 
move, and in case they won they were paid by check sent to them by mail. ${ }^{20}$

Ideally, subjects who take part in the experiment should be as similar as possible to the SOEP respondents, in particular with respect to the exogenous factors that explain individual risk attitudes. We tried to make the samples as similar as possible by adopting the exact same sampling methodology, and using the same surveying company as is used for the SOEP (for detailed documentation see also Schupp and Wagner, 2007). As the upper panel of Table 2 shows, the two samples are in fact quite similar. The fraction of females is 52.7 percent in the experiment and 51.9 percent in the SOEP data. Also, both mean age and median age of the participants are very similar. The same holds for height. This congruence reflects the representative character of the experimental subject pool. Table 2 also shows that the mean and median response to the general risk question is very similar. While the mean (median) value in the experiment is $4.76(5)$, it is $4.42(5)$ for the people who are interviewed in the SOEP. In addition, the answers to the general risk question are almost identically distributed. ${ }^{21}$

Closer investigation of the responses reveals that about 78 percent of the participants are risk averse. They prefer not to play the lottery, which has an expected value of 150 Euros, when offered a safe payment smaller than 150 Euros. About 13 percent are arguably risk neutral: 9 percent prefer a safe payment of 150 Euros to the lottery, but play the lottery at smaller alternative options, and 4 percent play the lottery when offered a safe payment equal to the expected value of the lottery but do not play the lottery when the safe payment exceeds the expected value of the lottery. About 9 percent of the subjects exhibit risk loving behavior, preferring the lottery to safe amounts above 150 Euros. These proportions of risk averse, risk neutral, and risk loving individuals

20 Sending checks is a particularly credible procedure in our case because the interviewers came from one of Germany's leading and most distinguished institutes in the field of social science survey research. None of the interviewers reported any credibility problems in their interviewer reports.

21 While a t-test rejects the null hypothesis that the mean response is identical in the two samples, we cannot reject the null hypothesis that the answers to the survey risk questions in the two samples have the same distribution on basis of a Kolmogorov-Smirnov-test. Furthermore, an interval regression using the specification in column (1) of Table 1 shows that determinants of responses to the general risk question are very similar across the two samples. For example, we cannot reject the null that the coefficients for gender, age, and height observed in the field experiment are the same as those observed in the SOEP survey sample. 
are closely in line with previous findings. ${ }^{22}$ There is some indication for the commonly observed tendency for subjects to switch at "prominent" numbers. We verify below that our results are robust to using smoothed measures of risk aversion that lump together switching rows into broader categories, and to using various estimation techniques that correct for potential censoring.

Our main interest in this section is whether survey data can predict actual risk taking behavior in the lottery experiment. In other words, we want to study whether greater willingness to take risks in the general risk question maps into a greater willingness to take risks in the lottery experiment. To test the predictive power of the general risk question, we ran the regressions reported in the lower panel of Table 2. In the first model, we simply regress the value of the safe option at the switching point on answers given to the general risk question. The coefficient on general risk is positive and significant at any conventional level, indicating that the answers given in the survey do predict actual risk taking behavior. To check robustness, we add controls in columns (2) and (3), which are essentially the same as the controls in Table 1. Specifically, controls in column (2) include gender, age, and height, and in Column (3) we control for many additional individual characteristics, as in Table A.1 in the Appendix. The general risk coefficient becomes somewhat smaller but stays significant at the one percent level. These results are also robust to alternative estimation approaches that use a smoothed version of the dependent variable, or adjust for potential censoring of the dependent variable. ${ }^{23}$ As an additional robustness check, we also estimated the same regressions as in Table 2, but weighting

${ }^{22}$ For example, in a condition with comparable stakes, Holt and Laury (2002) observe 81 percent risk averse, 13 percent risk neutral, and 6 percent risk loving. They use a similar choice-table procedure to obtain incentive compatible measures of risk preference, where switching rows categorize individuals into different intervals of risk aversion or risk-lovingness, although they vary the probabilities instead of the safe payment. See also Harrison et al., 2007, who use a similar measure and find a similar distribution of types in a representative sample of Danes.

23 We checked robustness to combining switching row information into six broader categories, each containing one of the prominent number spikes. We find that the general risk question is still a highly significant predictor of willingness to take risks in this case, confirming that prominent number effects do not explain the results. As an alternative approach we also estimated a Cox proportional hazard model, which accounts for the fact that individuals cannot switch beyond values of 190 . In this case we find that a higher value for the general risk scale has a highly significant negative impact on the hazard of switching to the safe option in the choice table (switching later in the choice table indicates greater willingness to take risks), which again confirms the behavioral validity of the general risk measure. 
responses to the general risk question in the field experiment by the respective fractions of responses to the general risk question in the SOEP sample. This makes the two samples exactly comparable in terms of the proportion of individuals choosing a given point on the general risk scale. We find similar results, indicating that the small differences between the two samples do not affect the generalizability of the validation results.

In summary, the answers to the general risk attitude question predict actual behavior in the lottery quite well. The results are robust even controlling for a wide array of observable characteristics, and using various estimation techniques, confirming the behavioral relevance of this survey measure.

\section{Determinants and Stability Across Contexts}

In this section we turn to the five questions that ask about willingness to take risks in the specific contexts of car driving, financial matters, sports and leisure, health matters, and career, respectively. We investigate the determinants of willingness to take risks in each context, to assess whether our results so far on gender, age, height, and parental education are robust to using alternative measures of risk attitudes. The analysis also sheds light on the deeper question of whether there is a stable trait determining risk-taking across different domains of life. In economics it is common to think of individuals as having an underlying risk preference that affects willingness to take risks in all contexts. By contrast, there is considerable controversy on this point in psychology (see Slovic, 1972a and 1972b; Weber et al., 2002). We contribute to the discussion in several ways. In a representative sample, we investigate whether the same factors determine risk attitudes across contexts. We also assess the strength of the correlation of willingness to take risks across contexts, and perform a principle component analysis to determine whether a single principle component determines risk taking in all contexts. 


\subsection{Determinants of Risk Attitudes in Different Contexts}

Table 3 explores the determinants of individual risk attitudes in each of the five specific contexts identified in the SOEP. For ease of comparison, the first column reports results for the general risk question, shown previously in column (2) of Table 1. Columns (2) to (6) show that the impact of the exogenous factors is, for the most part, qualitatively similar across contexts. ${ }^{24}$ Women are significantly less willing to take risks than men in all domains. This result is robust when adding the full set of controls. Gender differences are most pronounced for risk attitudes in car driving and financial matters, and least pronounced in the career domain. Increasing age reduces willingness to take risks in all five domains, but has a particularly large impact in the domain of sports and leisure, and a relatively small impact in financial matters. The table also shows that taller persons are more willing to take risks, in all domains. The height effect is particularly strong for car driving, sports and leisure, and career. The relationship between parental education and risk attitudes is less consistent across domains. Father's education has a positive and significant impact on risk taking in all contexts, and mother's education is important for risk taking in sports and leisure and career. Adding additional controls to the regressions has no impact on the qualitative results, and most effects remain similarly significant across domains, with the main exception of parental education, which becomes somewhat weaker. Regressions with all controls are reported in Table A.1 in the Appendix. ${ }^{25}$ In summary, these results provide further support for the importance of gender, age, height, and to a certain extent parental education, for determining willingness to take risks. The qualitatively similar impact of these factors across contexts is also suggestive of a common underlying risk preference.

\footnotetext{
24 The results are robust to estimating Ordered Probits, or OLS regressions.

25 The coefficient estimates are virtually identical in specifications using age splines with knots at 30 and 60 years of age, and are available upon request.
} 


\subsection{Stability of Risk Attitudes Across Contexts}

Mean responses for each context-specific question and the general risk question, reported in Table 4, suggest that context matters for self-reported willingness to take risks. ${ }^{26}$ The ranking of means in willingness to take risks, from greatest to least, is as follows: general, career, sports and leisure, car driving, health, and financial matters. The ranking is nearly identical for both men and women.

The next section in the table shows that risk attitudes are not perfectly correlated across contexts, but the pairwise correlations are large, typically in the neighborhood of 0.5, and all are highly significant. This is suggestive of a stable, underlying risk trait, but there also appears to be some sensitivity of risk attitudes to context. This could also reflect variation in risk preference, or other factors, such as subjective beliefs. ${ }^{27}$ For example, most people may view the typical risk in car driving as more dangerous than the typical risk in sports, and thus to state a relatively lower willingness to take risks in car driving. ${ }^{28}$

Principal components analysis using the general risk question and the five domainspecific questions tells a similar story. About 60 percent of the variation in individual risk attitudes is explained by one principal component, consistent with the existence of a single underlying trait determining willingness to take risks. ${ }^{29}$ All of the questions capture this underlying trait to some extent. ${ }^{30}$ Nevertheless, each of the other five components

26 The different number of observations across domains reflects different response rates. These differences may arise because individuals feel certain questions do not apply to them, e.g., a 90-year-old without a driver's license is free to leave blank the question about taking risks while driving a car.

27 Measurement error could also contribute to a less than perfect correlation across questions.

28 Evidence from psychology suggests that risk perceptions may vary across individuals and contexts. For example, women may perceive dangerous events (nuclear war, industrial hazards, environmental degradation, health problems due to alcohol abuse) as more likely to occur, in conditions where objective probabilities are difficult to determine (Silverman and Kumka, 1987; Stallen and Thomas, 1988; Flynn et al., 1994; Spigner et al., 1993). Differences in risk perception could indicate that beliefs are formed based on systematically different information sets. Alternatively, biases due to emotion (e.g., fear or dread), or overconfidence, could play a role in explaining different risk perceptions (Slovic, 1999; Loewenstein et al., 2001).

29 The eigenvalue associated with this component equals 3.61 while the eigenvalues associated with all other components are smaller than 0.57 . When only one component is retained, none of the off-diagonal elements of the residual correlation matrix exceeds $|0.11|$.

30 The factor loadings for the different risk questions on the principal component are 0.78 (general), 0.76 (car driving), 0.74 (financial matters), 0.80 (sports and leisure), 0.81 (career), and 0.75 (health). 
explains at least five percent of the variation. This again suggests that the individual measures do capture some additional, context-specific content, as well as capturing a trait that is common across contexts and pure measurement error.

\section{$5 \quad$ Survey Risk Measures and Risky Behaviors}

The last part of our analysis returns to the issue of behavioral validity. Previously we demonstrated the ability of the general risk measure to predict real-stakes lottery choices in a field experiment. In this section we study a broader range of risky behaviors, encompassing a variety of important economic and social contexts, and test the validity of all six risk measures. In so doing, we hope to answer three questions. First, are the survey instruments useful for explaining and predicting risky behavior, in terms of both statistical and economic significance. Secondly, can the individual risk measures explain risky behaviors in multiple contexts? Third, how do the different risk measures compare in terms of explanatory and predictive power? In particular, how does the general risk question as global measure of risk attitudes perform in comparison to context-specific measures in a particular context? For example, is smoking best predicted by a health related risk question or is it equally well explained by the general risk? The answer to these questions is of obvious importance from both a methodological and a practical point of view.

To address our questions we use a collection of behaviors reported by the SOEP participants. We choose behaviors that span the different contexts identified by the five domain-specific questions: portfolio choices (financial context), participation in sports (sports and leisure), self-employment (career), and smoking (health). All of these risky behaviors are measured as binary variables and are displayed in Table 5, with the exception of traffic offenses, which are analyzed separately at the end of the section. As a proxy for portfolio choice we use information about household stock holdings. The variable "Investment in Stocks," shown in column (1), is equal to 1 if at least one household member holds stocks, shares, or stock options and zero otherwise. Since the question 
about stock holdings is typically answered by the household head, we use observations on risk preferences of household heads in column (1) only. In the context of sports, the variable "Active Sports" takes a value of 1 if an individual actively participates in any sports (at least once per month). The variable "Self-Employment" is a binary variable equal to 1 if an individual is self-employed and zero otherwise. To study risk-taking behavior in the domain of health, we use information about whether the SOEP participant smokes or not. The corresponding variable is equal to 1 if the respondent smokes.

Each reported coefficient estimate shown in Table 5 is based on a separate regression of the respective behavior on this particular risk measure and a set of controls. ${ }^{31}$ For these regressions we use standardized versions of the risk measures, to aid comparison of coefficients across regressions. The regressions are Probit models, and coefficients are marginal effects showing the impact of a one standard deviation change in the corresponding measure of willingness to take risks. We report the standard errors of the coefficients in brackets, and the log likelihoods in parentheses. For example, the three entries in the upper left corner in column (1) say that the willingness to take risks in general is significantly correlated with investments in stocks, the marginal effect being 0.029. The standard error of the coefficient is 0.006 and the log likelihood for this regression is $-3,993$. Coefficient estimates for the controls are not reported but are available on request. Each column in the table also reports the unconditional probability of observing the corresponding risky behavior.

Several observations can be made from Table 5. First, all measures are significant explanatory variables for at least some of the behaviors, providing further confirmation of their behavioral validity. The marginal effects are also sizeable relative to the unconditional probabilities, showing the economic significance of the risk attitude measures. Second, the general risk question is significant in all contexts, with relatively large coefficients and goodness of fit. Third, each context-specific risk question explains behavior in

${ }^{31}$ In every regression the controls include gender, age, height, and parental education, as in column (2) of Table 1, but also log household wealth, log household debt, and the log of current gross monthly household income. One exception is the regression for stock holdings, where we also control for the number of household members older than 18 , because the likelihood that at least one person in the household holds risky assets is increasing with household size. 
its respective context, and is typically the strongest risk measure for this context. Again, this can been seen by comparing the size of the marginal effects and the log likelihoods of the different regressions.

Investment in stocks, shown in column (1), is positively correlated with several risk measures, as expected given the relative riskiness of this kind of financial investment. The best predictor is the context-specific risk measure on "Financial Matters". The log likelihood for this regression is larger than for any other regression based on a different risk measure, and the marginal effect is also larger. Notably, the marginal effect is economically significant: a one standard deviation increase in willingness to take risks in financial matters is associated with a 34 percent increase in the probability of holding stocks (relative to the unconditional probability). This implies that the exogenous determinants of risk attitudes in the financial context, shown in Table 3, are also quantitatively important, through the channel of changing risk attitudes. For example, the gender coefficient in column (3) of Table 3 was -0.77 . Given that the standard deviation of willingness to take risks in financial matters is 2.225 (see Table 4), this is a decrease of about a third of a standard deviation. The results in Table 5 then imply that a quarter standard deviation decrease in willingness to take risks is associated with a 12 percent decrease in the probability of holding stocks. ${ }^{32}$ Analogous calculations show that any one of the following - 20 fewer years of age, 20 additional centimeters of height, or having two highly-educated parents - would increases the probability of holding stocks by about 8 percent, through the indirect channel of changing willingness to take risks. ${ }^{33}$

Column (2) of Table 5 shows that being active in sports is strongly correlated with several risk measures, but the measure of risk taking in "Sports and Leisure" is the most important in terms of statistical and economic significance. A one standard deviation increase in willingness to take risks in the context of sports is associated with about a 22

32 Thus, gender has a sizeable indirect effect on the probability of holding stocks through the channel of risk attitudes. This is also sizeable relative to the direct effect of gender on holding stocks (controlling for risk attitudes in financial matters and other characteristics). The (unreported) estimated marginal effect for gender in Table 5, in the regression involving risk attitudes in financial matters, is -0.083 .

33 The impact through the channel of the general risk attitude is smaller, in any given context, than through the corresponding context-specific attitude. The total impact of a change in general risk attitudes, however, is substantial. 
percent increase in the probability of participating in active sports. ${ }^{34}$

In column (3) we investigate the relationship between risk attitudes and career choice. Given the low degree of job security and high income variability associated with self-employment, we would expect that relatively risk-averse people choose not to become self-employed. In fact, the coefficients on the risk measures are significant and positive, consistent with those who are more willing to take risks being more likely to choose selfemployment. Exceptions include risk attitudes in sports and leisure, which are unrelated to being self-employed. ${ }^{35}$ Notably, willingness to take risks in career matters is the overall best predictor of self-employment, in terms of significance, fit, and size of the marginal effect. A one standard deviation increase in willingness to take risks in the career context is associated with a 43 percent increase in the likelihood of being self-employed. ${ }^{36}$

In column (4) we turn to risky health behavior in the form of smoking. Willingness to take risks in general has a strong positive impact on the propensity to smoke, but willingness to take risks in the domain of health has an even greater impact, as indicated by the larger marginal effect and the higher log likelihood. The case of smoking is of particular interest given that smoking has been used as an instrument for risk attitudes, in cases where direct measures of risk attitude were not available (e.g., Feinberg, 1977). In light of results in column (5), however, smoking can only be considered a very imperfect substitute for more direct measures of risk attitudes. While smoking is strongly associated with the willingness to take risks in the health domain, it is less correlated or not correlated at all with risk attitudes in other domains such as financial matters or sports and leisure. The impact of a one standard deviation increase in willingness to take risks in health

${ }^{34}$ Because gender and age affect willingness to take risks in the context of sports $(s . d .=2.613)$, being female, or 20 years older, decreases the probability of participating in sports by about 5 or 10 percent, respectively. Through the channel of changing risk attitudes, 20 additional centimeters of height increases the probability of participating in sports by about 6 percent, and having two parents with the Abitur is associated with an increase of about 7 percent.

${ }^{35}$ For related evidence on risk aversion and entrepreneurship, see Cramer et al. (2002).

36 The impact of being female, or 20 years older, that works through the channel of willingness to take risks in career matters $($ s.d. $=2.71)$, is an 9 percent or 18 percent decrease in the likelihood of being self-employed, respectively. 20 additional centimeters of height, or having two parents with the Abitur, increases the probability of being self-employed by 12 percent or 10 percent, respectively, through the channel of greater willingness to take risks in career matters. 
matters is a 20 percent increase in the probability of being a smoker. ${ }^{37}$

In additional (unreported) regressions we also tested the relative explanatory power of the different risk measures by regressing a given behavioral outcome on all of the measures simultaneously. The results are very similar to the ones in Table 5 , in the sense that the corresponding domain specific risk question is the best predictor of investment in stocks, participation in sports, self-employment, and being a smoker. ${ }^{38}$

\section{Discussion}

This paper contributes evidence on several open questions regarding the measurement and nature of individual risk attitudes. Using a simple survey measure that asks people to give a global assessment of their willingness to take risks in general, we find an economically significant impact of gender, age, height, and parental background on individual willingness to take risks. The behavioral validity of the survey measure is verified in complementary, incentive compatible field experiment conducted using a representative subject pool. The results on determinants of risk attitudes are robust to using other survey measures that ask about risk taking in specific contexts. Risk attitudes are shown to be relatively stable across different contexts, shedding light on a deeper question about stability of willingness to take risks as a personal trait. All of the survey measures are shown to explain various risky behaviors, including holding stocks, smoking, self-employment, and participation in active sports. The best all-around predictor is the general risk question. On the other hand, asking about risk attitudes in a more specific context gives a stronger measure for the corresponding context.

The findings on the determinants of risk attitudes have important implications. For example, previous experimental research has documented that women are less will-

37 Through the channel of willingness to take risks in health matters $(s . d .=2.465)$, being female, or being 20 years older, reduces the probability of smoking by 6 percent, respectively. The change in risk attitudes due to 20 additional centimeters of height, or the impact of two highly educated parents on risk attitudes increases the probability of smoking by about 3 percent, respectively.

${ }^{38}$ We also compared the performance of the different risk measures in terms of prediction accuracy when splitting the sample and using the estimates from one subsample to predict behavior in the other subsample. Detailed results are available upon request. 
ing to sort into relatively risky, tournament compensation schemes (e.g., Niederle and Vesterlund, 2007). A gender difference in willingness to take risks could be part of the explanation for this important difference in behavior. In fact, another study also finds that women prefer less risky compensation over tournaments (Dohmen and Falk, 2006), but also asks our general risk question. They find that lower willingness to take risks among females explains a substantial part of the gender difference in sorting decisions. An age profile for risk attitudes could also be important, for explaining behavior at the macroeconomic level: demographic changes leading to a more elderly population are predicted to lead to a more conservative pool of investors and voters, which could substantially influence macroeconomic performance and political outcomes, increase the resistance to reforms, and delay necessary but potentially risky policy adjustments. A role for parental education in shaping the risk attitudes of children highlights a potentially important role of education policy, and has implications for understanding intergenerational correlations in economic outcomes and social mobility. The impact of height on risk attitudes could be relevant for explaining another important puzzle, namely the documented relationship between height and labor market earnings. ${ }^{39}$

The results of this paper also have implications for measuring risk attitudes in selfreported surveys. They indicate that the approach of asking people for a global assessment of willingness to take risks in fact generates a useful all-around measure. Asking questions that include more specific contexts produce measures that are even stronger, for that given context. On the other hand, focusing on a single context provides less predictive power across contexts. In light of these findings, the usual practice of only eliciting risk attitudes in the context of hypothetical financial lotteries would be expected to have benefits for predicting financial decisions, but be a less effective approach for providing a summary statistic of risk attitudes across other non-financial contexts. The SOEP does include a hypothetical lottery question, which asks people how much of an endowment

39 Persico et al. (2004) find that height in adolescence, more than height in adulthood, has an impact on wages later in life. The authors' hypothesis is that the height effect is due to the impact of height in adolescence on confidence and self-esteem. Our results suggest that another by-product could be greater willingness to take risks, which is a plausible channel leading to higher future wages. 
of 100,000 Euros they would invest in an asset that doubles or returns only half of the investment with equal probability. In unreported results, available upon request, we find that answers to the hypothetical lottery are in fact strong predictors for decisions in the financial domain, in the sense that they predict holding stocks. On the other hand, responses to the lottery do not predict self-employment, or smoking, consistent with the hypothesis that the more narrow context produces a measure that is less informative for risk taking in non-financial domains. It is noteworthy that we also find similarly robust results on the impact of gender, age, and height using the lottery measure, showing that these findings also prevail in measures that involve financial lotteries and explicit stakes and probabilities. Responses to the general risk question are highly correlated with choices in the hypothetical lottery question, providing an additional indication that the general risk question has explanatory power for choices in financial lotteries. ${ }^{40}$

Our validation of the general risk question provides a valuable instrument for future research using survey data, where a simple and low cost measure of risk attitudes is very often needed. For example, once one is confident that a measure captures risk attitudes in a behaviorally relevant way, it is possible to test theoretical predictions regarding the relationship between risk attitudes and a given behavior, for example whether people who are risk averse are more or less likely to be geographically mobile. Alternatively, it may be important to control for risk attitudes in a regression, if risk attitudes determine some type of selection process that confounds interpretation of a different variable of interest. We have taken this next step in some of our own research. For example, Bonin et al. (2007) use the general risk question, and show that individuals who are willing to take risks sort into occupations with higher cross-sectional earnings risk. Jaeger et al. (2007) show that willingness to take risks has a significant impact on geographic mobility. Two

${ }^{40}$ In fact, if one assumes CRRA utility, responses to the general risk question can be mapped into CRRA coefficients using a combination of individuals responses to the lottery question and individual wealth information. Lottery responses and wealth information imply a distribution of CRRA coefficients mainly between 1 and 10. The mapping to the general risk question indicates that for an individual with zero wealth, choosing zero on the general risk scale is equivalent to a CRRA coefficient of approximately 2.9. For a given wealth level, one additional point on the general risk scale is associated with a decrease in the CRRA coefficient of 0.381 , while a larger wealth level implies a larger CRRA coefficient, holding the degree of risk-taking constant. 
other recent papers have also taken advantage of the experimentally-validated general risk question. Grund and Sliwka (2006) find support for the theoretical prediction that risk attitudes determine sorting into performance pay jobs, and Caliendo et al. (2009) show that willingness to take risks increases the probability that an individual becomes an entrepreneur in the future. We believe that these studies are the tip of the iceberg, in terms of applications for validated survey measures of risk attitudes. 


\section{References}

Barr, A., and T. PACKARd (2002): "Revealed Preference and Self-Insurance: Can We Learn from the Self-Employed in Chile?," World Bank Policy Research Working Paper No. 2754.

Barsky, R. B., T. F. Juster, M. S. Kimball, and M. D. Shapiro (1997): "Preference Parameters and Individual Heterogeneity: An Experimental Approach in the Health and Retirement Study," Quarterly Journal of Economics, 112(2), 537-579.

Bellemare, C., and S. KröGer (2007): "On Representative Social Capital," European Economic Review, 51(1), 181-202.

Binswanger, H. P. (1980): "Attitudes Towards Risk: Experimental Measurement in Rural India," American Journal of Agricultural Economics, 62(3), 395-407.

Blackburn, M., G. W. Harrison, and E. E. Rutstrom (1994): "Statistical Bias Functions and Informative Hypothetical Surveys," American Journal of Agricultural Economics, 76(5), 1084-1088.

Blinder, A. (1973): "Wage Discrimination: Reduced Form and Structural Estimates," Journal of Human Resources, 8(3), 436-455.

Bonin, H., T. Dohmen, A. Falk, D. Huffman, and U. Sunde (2007): "CrossSectional Earnings Risk and Occupational Sorting: The Role of Risk Attitudes," Labour Economics, 14(6), 926-937.

Bruhin, A., H. Fehr-DudA, And T. Epper (2007): "Risk and Rationality: Uncovering Heterogeneity in Probability Distortion," SOI Working Paper No. 0705.

Camerer, C. F., and R. M. Hogarth (1999): "The Effects of Financial Incentives in Experiments: A Review and Capital-Labor-Production Framework," Journal of Risk and Uncertainty, 19(1), 7-42. 
Champ, P. A., And R. C. Bishop (2001): "Donation Payment Mechanisms and Contingent Valuation: An Empirical Study of Hypothetical Bias," Environmental and Resource Economics, 19, 383-402.

Choi, S., R. Fisman, D. Gale, and S. Kariv (2007): "Consistency and Heterogeneity of Individual Behavior Under Uncertainty," American Economic Review, 97(5), 19211938.

Cramer, J. S., Joop Hartog and Nicole Jonker and C. Mirjam van PraAg (2002): "Low Risk Aversion Encourages the Choice for Entrepreneurship: an Empirical Test of a Truism," Journal of Economic Behavior and Organization, 48(1), 29-36.

Diaz-Serrano, L., and D. O’Neill (2004): "The Relationship Between Unemployment and Risk-Aversion," IZA Discussion Paper No. 1214.

Dohmen, T., And A. Falk (2006): "Performance Pay and Multidimensional Sorting: Productivity, Preferences and Gender," IZA Discussion Paper No. 2001.

Dohmen, T., A. Falk, D. Huffman, U. Sunde, J. Schupp, and G. G. WagNER (2005): "Individual Risk Attitudes: New Evidence from a Large, Representative, Experimentally-Validated Survey," IZA Discussion Paper No. 1730.

Donkers, B., B. Melenberg, And A. V. Soest (2001): "Estimating Risk Attitudes Using Lotteries: A Large Sample Approach," Journal of Risk and Uncertainty, 22(2), $165-195$.

Eckel, C., and P. Grossman (2007): "Men, Women and Risk Aversion: Experimental Evidence," in Handbook of Experimental Results, ed. by C. Plott, and V. Smith, NorthHolland. Elsevier Science.

Eckel, C., C. Johnson, And C. Montmarquette (2005): "Saving Decisions of the Working Poor: Short- and Long-Term Horizons," in Research in Experimental Economics Volume 10: Field Experiments in Economics, ed. by J. Carpenter, G. Harrison, and J. List, pp. 219-260, Oxford. Elsevier Science. 
FeinberG, R. M. (1977): "Risk-aversion, Risk and the Duration of Unemployment," Review of Economics and Statistics, 59(3), 264-271.

Flynn, J., P. Slovic, And C. Mertz (1994): "Gender, Race, and Perception of Environmental Health Risks," Risk Analysis, 14, 1101-1108.

Grund, C., And D. Sliwka (2006): "Performance Pay and Risk Aversion," IZA Discussion Paper No. 2012.

Guiso, L., T. Jappelli, And L. Pistaferri (2002): “An Empirical Analysis of Earnings and Employment Risk," Journal of Business and Economic Statistics, 20(2), 241253.

Guiso, L., And M. Paiella (2001): "Risk-Aversion, Wealth, and Background Risk," CEPR Discussion Paper No. 2728.

(2005): "The Role of Risk Aversion in Predicting Individual Behavior," Bank of Italy Economic Working Paper No. 546.

Harrison, G. W., M. I. Lau, and E. E. Rutström (2007): "Estimating Risk Attitudes in Denmark: A Field Experiment," Scandanavian Journal of Economics, 109(2), $341-368$.

Holt, C. A., And S. K. Laury (2002): "Risk Aversion and Incentive Effects," American Economic Review, 92(5), 1644-1655.

LAury, S. L. (2006): "Pay One or Pay All," EXCEN Working Paper No. 2006-24, Georgia State University.

Loewenstein, G. F., C. K. Hsee, E. U. Weber, and N. Welch (2001): "Risk as Feelings," Psychological Bulletin, 127(2), 267-286.

Niederle, M., And L. Vesterlund (2007): "Do Women Shy Away From Competition? Do Men Compete Too Much?," Quarterly Journal of Economics, 122(3), forthcoming. 
OAxacA, R. (1973): "Male-Female Wage Differentials in Urban Labor Markets," International Economic Review, 14(3), 693-709.

Persico, N., A. Postlewaite, and D. Silverman (2004): "The Effect of Adolescence Experience on Labor Market Outcomes: The Case of Height," Journal of Political Economy, 112(5), 1019-1053.

SARIs, W. E. (2003): "Multitrait-Multimethod Studies," in Cross-Cultural Survey Methods, ed. by J. Harkness, pp. 265-274, New Jersey. Hoboken.

Saris, W. E., And A. van Meurs (1990): "Memory Effects in MTMM Studies," in Evaluation of Measurement Instruments by Meta-Analysis of Multitrait Multimethod Studies, ed. by W. Saris, and A. van Meurs, pp. 134-146, Amsterdam. North-Holland.

SchäFer, A., AND J. Schupp (2006): "Zur Erfassung der Vermögensbestände im Soziooekonomischen Panel (SOEP) im Jahr 2002," DIW Data Documentation, 11.

Schubert, R., M. Brown, M. Gysler, and H. Brachinger (1999): "Financial Decision-Making: Are Women Really More Risk-Averse?," American Economic Review Papers and Proceedings, 89(2), 381-385.

Schupp, J., And G. G. Wagner (2002): "Maintenance of and Innovation in Long-Term Panel Studies The Case of the German Socio-Economic Panel (GSOEP)," Allgemeines Statistisches Archiv, 86(2), 163-175.

(2007): "New Sources for Theory Based Socio-Economic Behavioral Analysis: The 2002-2006 Pre-Tests for the German Socio-Economic Panel Study," DIW Data Documentation, in press.

Silverman, J. M., And D. S. Kumka (1987): "Gender Differences in Attitudes Towards Nuclear War and Disarmament," Sex Roles, 16, 189-203.

Slovic, P. (1972a): "Psychological Study of Human Judgment: Implications for Investment Decision Making," Journal of Finance, 27, 777-799. 
(1972b): "Information Procession, Situation Specificity, and the Generality of Risk-Taking Behavior," Journal of Personality and Social Psychology, 22, 128-134.

- (1999): "Trust, emotion, sex, politics, and science: Surveying the risk-assessment battlefield," Risk Analysis, 19(4), 689-701.

Spigner, C., W. Hawkins, and W. Lorens (1993): "Gender Differences in Perception of Risk Associated with Alcohol and Drug Use Among College Students," Women and Health, 20, 87-97.

Stallen, P., and A. Thomas (1988): "Public Concern About Industrial Hazards," Risk Analysis, 8, 237-245.

Thompson, S. K. (2006): "Targeted Random Walk Designs," Survey Methodology, $32(1), 11-24$.

Wagner, G. G., R. V. Burkhauser, and F. Behringer (1993): "The English Language Public Use File of the German Socio-Economic Panel," The Journal of Human Resources, 28(2), 429-433.

Weber, E. U., A. R. Blais, and N. E. Betz (2002): "A Domain-Specific RiskAttitude Scale: Measuring Risk Perceptions and Risk Behaviors," Journal of Behavioral Decision Making, 15, 263-290. 
Tables 


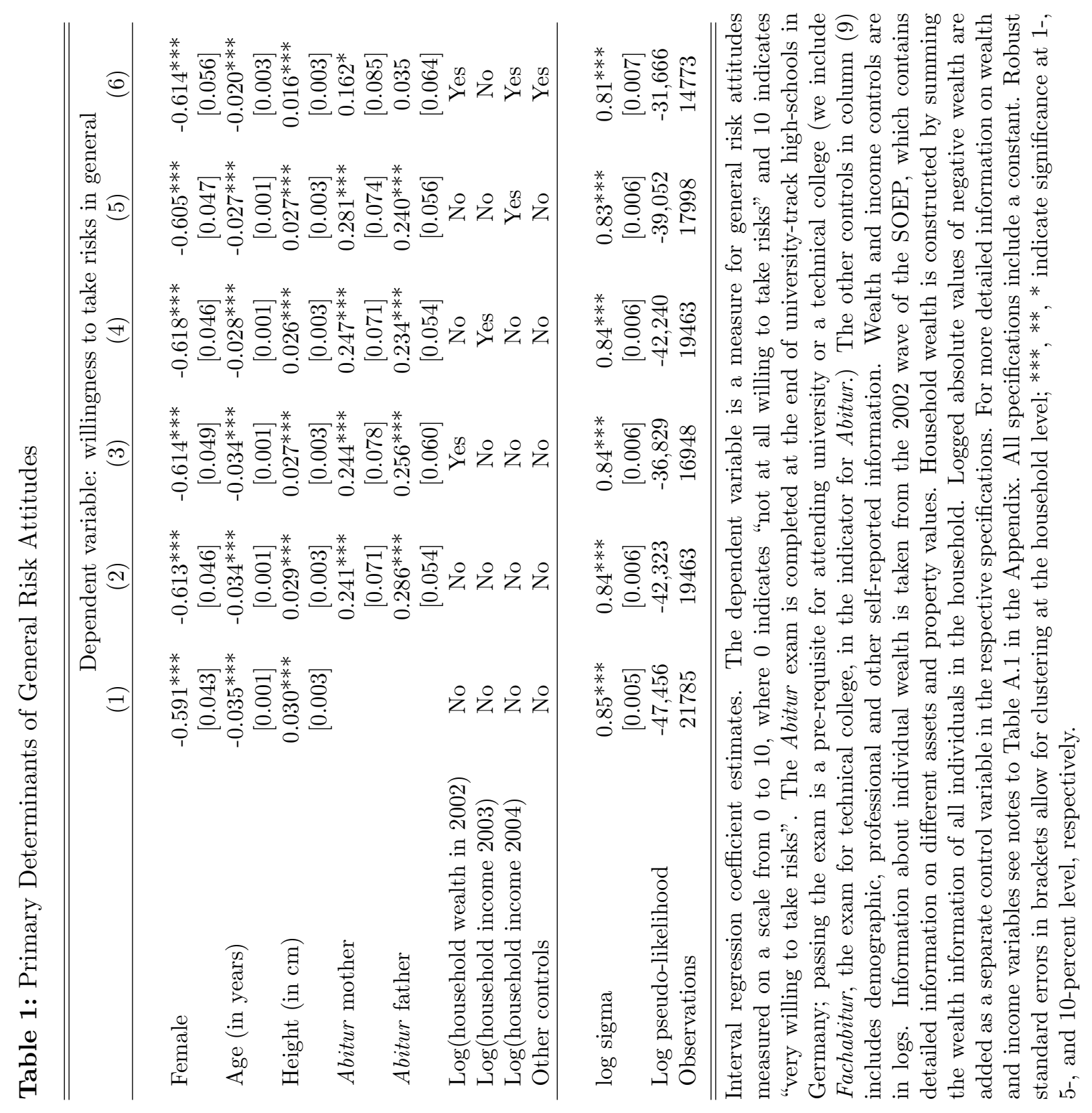


Table 2: Validation of Survey Risk Measure in a Field Experiment

\begin{tabular}{lcccccc}
\hline \hline & \multicolumn{3}{c}{ Subjects in experiment } & \multicolumn{3}{c}{ SOEP respondents } \\
& Mean & std. dev. & Median & Mean & std. dev. & Median \\
\hline & & & & & & \\
Fraction female & 0.527 & 0.50 & & 0.519 & 0.50 & \\
Age (in years) & 47.77 & 18.40 & 47 & 47.17 & 17.43 & 46 \\
Height (in cm) & 171.73 & 9.09 & 172 & 171.39 & 9.27 & 170 \\
& & & & & & \\
General risk attitude (survey response) & 4.76 & 2.54 & 5 & 4.42 & 2.38 & 5 \\
\hline & & & & & & \\
Observations & 450 & 450 & 450 & 21,875 & 21,875 & 21,875 \\
\hline \hline
\end{tabular}

(a) Comparison of SOEP and Experimental Sample

\begin{tabular}{lccc}
\hline \hline \multicolumn{4}{c}{ Dependent variable: value of safe option at switch point } \\
& $(1)$ & $(2)$ & $(3)$ \\
\hline \multirow{3}{*}{ Willingness to take risk in general } & $0.611^{* * *}$ & $0.484^{* * *}$ & $0.401^{* * *}$ \\
& {$[0.123]$} & {$[0.125]$} & {$[0.131]$} \\
& & & \\
Controls for gender, age, height & No & Yes & Yes \\
Other controls & No & No & Yes \\
& & & \\
Constant & $5.919^{* * *}$ & -5.923 & -14.287 \\
& {$[0.661]$} & {$[7.916]$} & {$[10.724]$} \\
\hline log sigma & $1.867^{* * *}$ & $1.848^{* * *}$ & $1.736^{* * *}$ \\
& {$[0.037]$} & {$[0.037]$} & {$[0.040]$} \\
Log pseudo-likelihood & $-1,348$ & $-1,341$ & $-1,111$ \\
Observations & 450 & 450 & 383 \\
\hline \hline
\end{tabular}

(b) Predicting Lottery Choices with Survey Measure Risk Attitudes

Interval regression coefficient estimates. The dependent variable is the value of the safe option at the switching point. Other controls include controls for marital status, number of dependent children under 16, lived in GDR in 1989, lived Abroad in 1989, location in 1989 missing, nationality, student, educational achievement, dummies for occupational level within public and private sector (as in Table A.1) in the Appendix), health status, body weight, net household income, and life satisfaction, compare also Table A.1. Robust standard errors in brackets; ***, **, * indicate significance at 1-, 5-, and 10-percent level, respectively. 


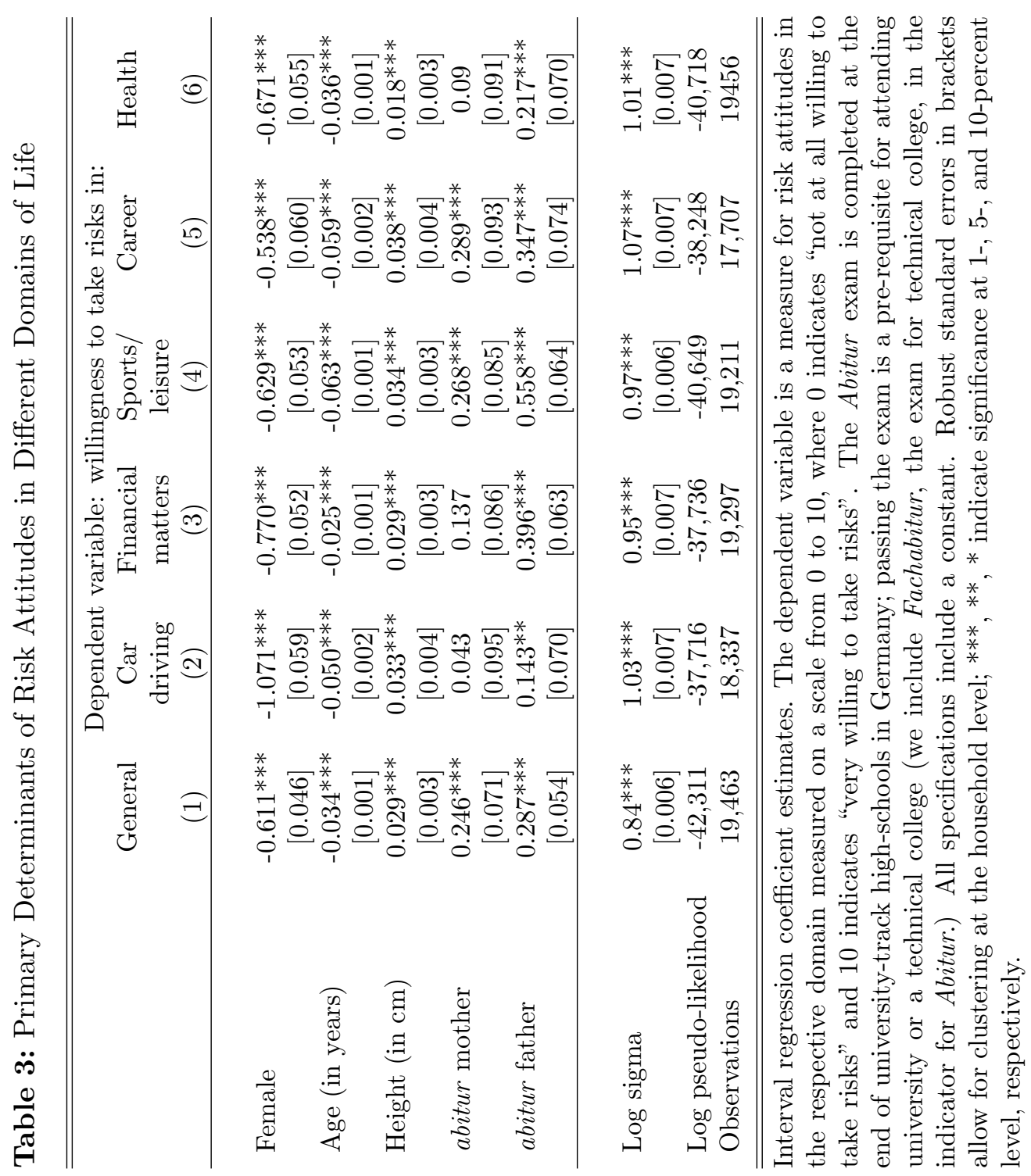



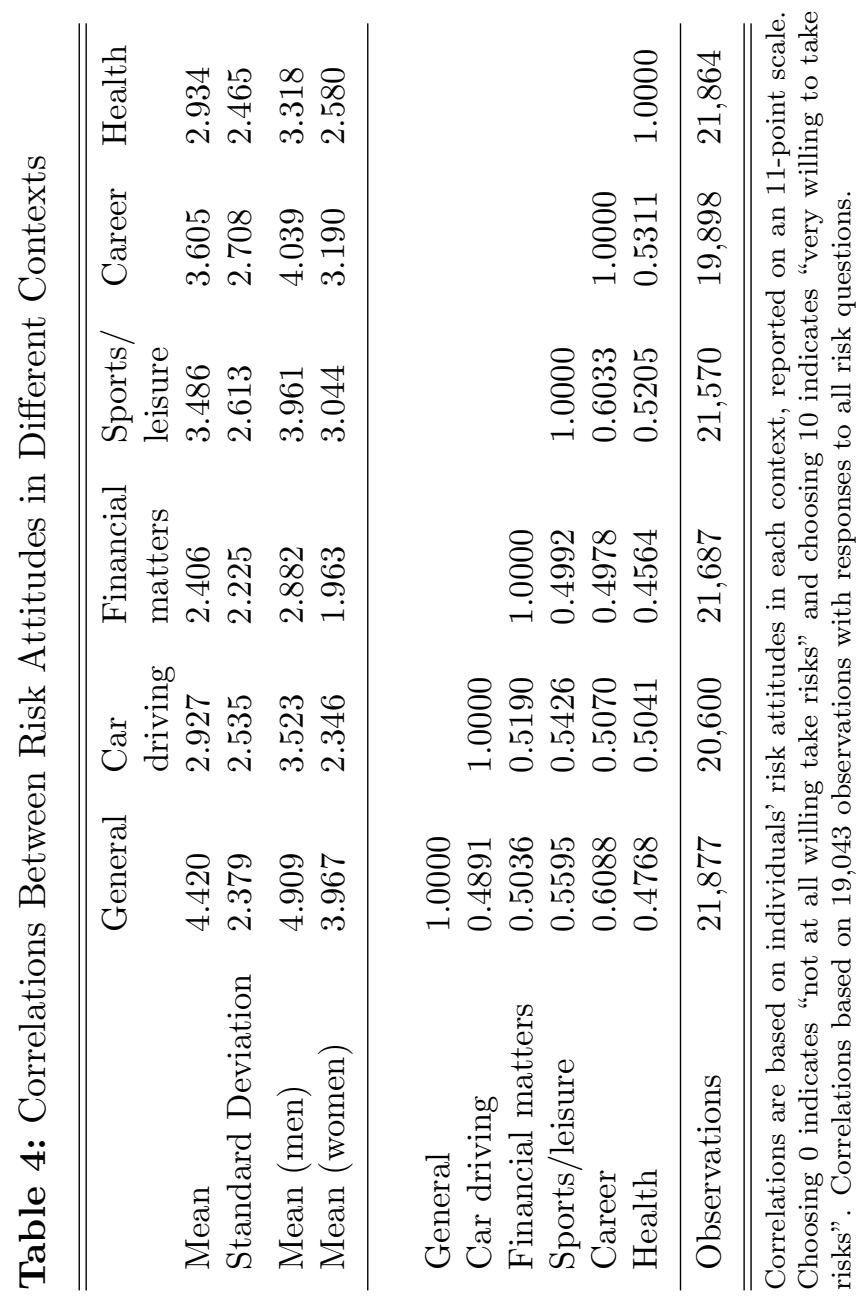
Table 5: The Relative Ability of Alternative Measures of Risk Attitudes to Explain Risky

Behaviors

\begin{tabular}{lcccc}
\hline \hline Dependent variable: & $\begin{array}{c}\text { Investment } \\
\text { in stocks }\end{array}$ & Active sports & Self-employed & Smoking \\
& $(1)^{\dagger}$ & $(2)$ & $(3)^{\ddagger}$ & $(4)$ \\
\hline \hline Willingness to take risks in & $0.029^{* * *}$ & $0.061^{* * *}$ & $0.024^{* * *}$ & $0.037^{* * *}$ \\
general & {$[0.006]$} & {$[0.005]$} & {$[0.003]$} & {$[0.004]$} \\
& $(-3,993)$ & $(-7,426)$ & $(-2,599)$ & $(-7,772)$ \\
Willingness to take risks in & & & & \\
Car driving & $0.024^{* * *}$ & $0.037^{* * *}$ & $0.007^{* *}$ & $0.018^{* * *}$ \\
& {$[0.006]$} & {$[0.005]$} & {$[0.003]$} & {$[0.004]$} \\
Financial matters & $(-3,996)$ & $(-7,489)$ & $(-2,636)$ & $(-7,801)$ \\
& $0.117^{* * *}$ & $0.063^{* * *}$ & $0.013^{* * *}$ & -0.003 \\
Sports and leisure & {$[0.006]$} & {$[0.005]$} & {$[0.003]$} & {$[0.004]$} \\
& $(-3,799)$ & $(-7,425)$ & $(-2,626)$ & $(-7,810)$ \\
& $0.052^{* * *}$ & $0.143^{* * *}$ & 0.003 & 0.002 \\
Career & {$[0.006]$} & {$[0.005]$} & {$[0.003]$} & {$[0.005]$} \\
& $(-3,969)$ & $(-7,075)$ & $(-2,638)$ & $(-7,810)$ \\
& $0.035^{* * *}$ & $0.065^{* * *}$ & $0.036^{* * *}$ & $0.025^{* * *}$ \\
Health & {$[0.006]$} & {$[0.005]$} & {$[0.003]$} & {$[0.004]$} \\
& $(-3,987)$ & $(-7,419)$ & $(-2,539)$ & $(-7,793)$ \\
& $0.023^{* * *}$ & $0.029^{* * *}$ & $0.012^{* * *}$ & $0.060^{* * *}$ \\
& {$[0.006]$} & {$[0.005]$} & {$[0.003]$} & {$[0.004]$} \\
Observations & $(-3,997)$ & $(-7,499)$ & $(-2,628)$ & $(-7,704)$ \\
\hline \hline & 7,345 & 13,520 & 9,897 & 13,571 \\
& 0.341 & 0.662 & 0.084 & 0.294 \\
\hline
\end{tabular}

Dependent variables in all columns are binary variables. Willingness to take risks is measured on on a scale from 0 to 10, where 0 indicates "not at all willing to take risks" and 10 indicates "very willing to take risks". All risk measures are standardized. Reported coefficients are Probit marginal effects estimates, evaluated at the means of independent variables. Each coefficient estimate is based on a separate regression of the respective dependent variable on this particular risk measure and a set of controls, whose coefficient estimates are not reported. This set includes the same controls for gender, age, height, and parental education as in Table 1, as well as controls for log household wealth, log household debt, and the log of current gross monthly household income in every regression. Additional controls: † Number of Adults in household. $\ddagger$ Sample excludes individuals that are older than 66 years, or retired, or non-participating in the labor market. All specifications include a constant. Robust standard errors that allow for clustering at the household level are reported in brackets below the coefficient estimates. Values of the log pseudo-likelihood of the respective regression model are reported in parentheses; ***, **,* indicate significance at 1-, 5-, and 10-percent level, respectively. 
Figures

Figure 1: Willingness to Take Risks in General

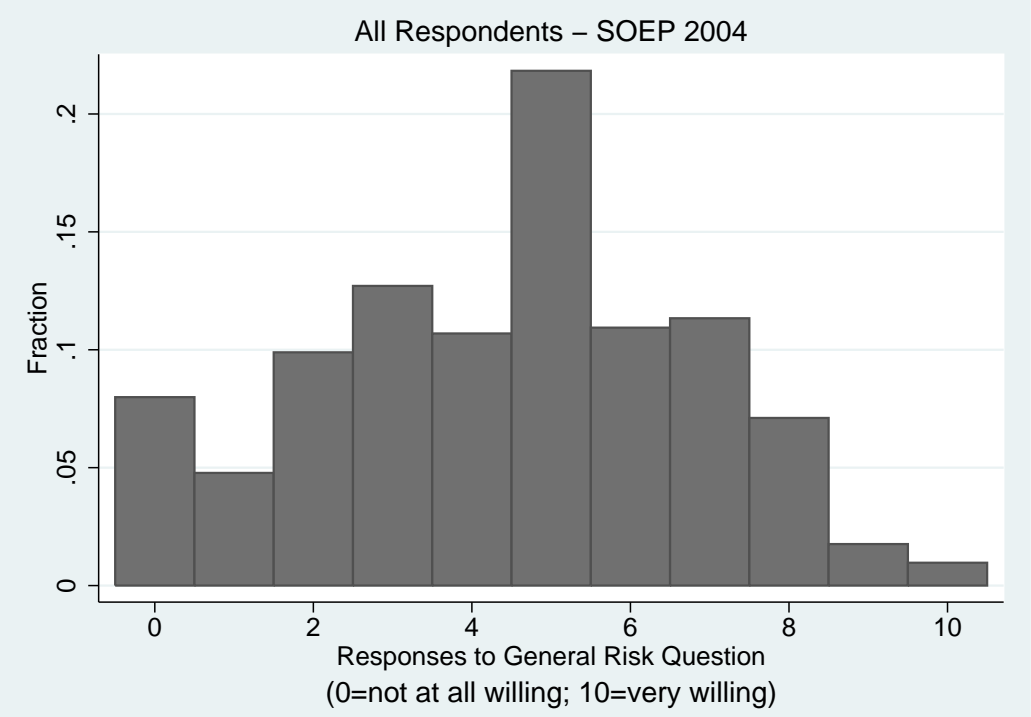

Notes: The Figure shows a histogram of responses to the question about willingness to take risks "in general", measured on an eleven-point scale. 


\section{A Appendix}

Table A.1: Determinants of Risk Attitudes

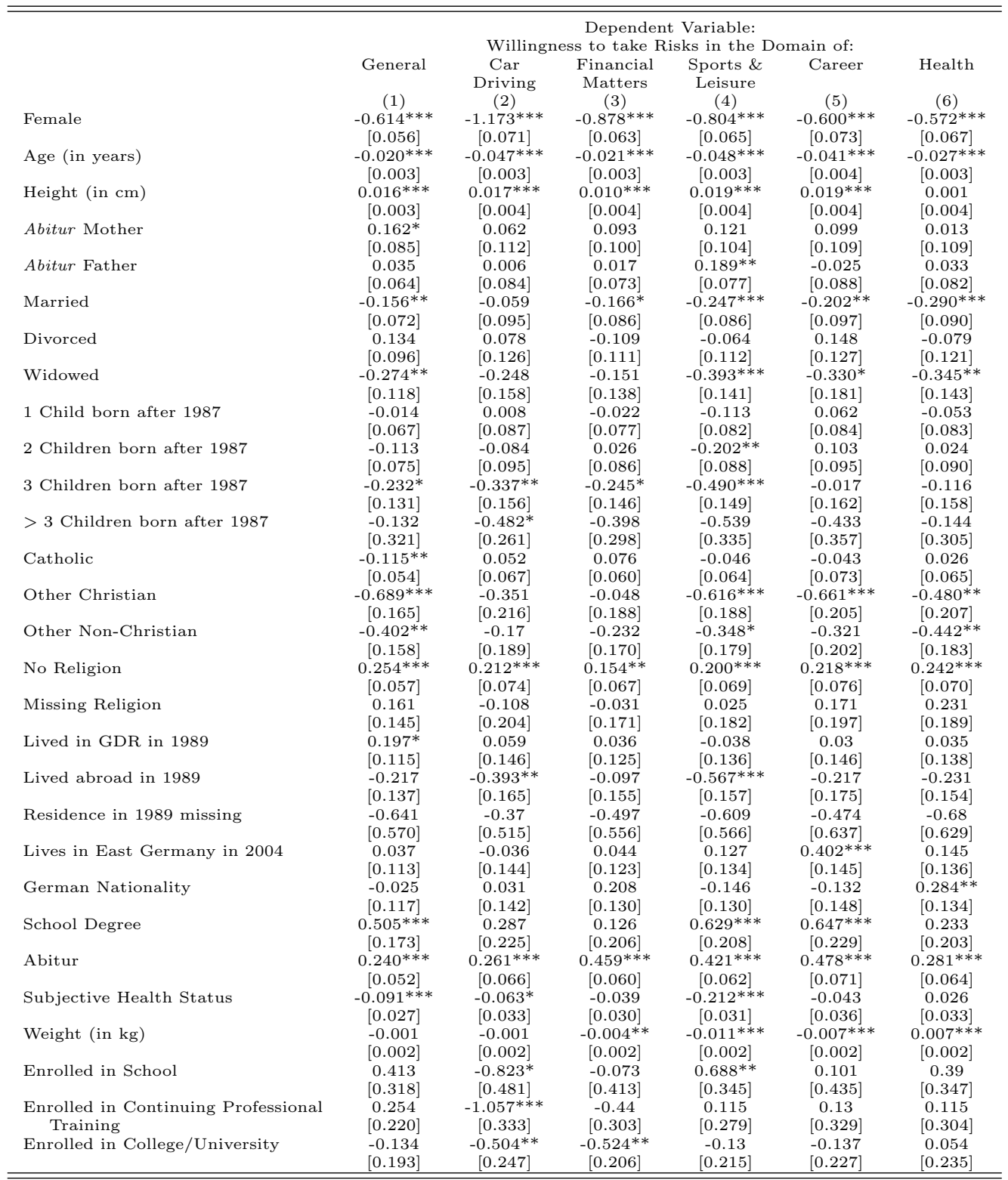


Table A.1: continued: Determinants of Risk Attitudes

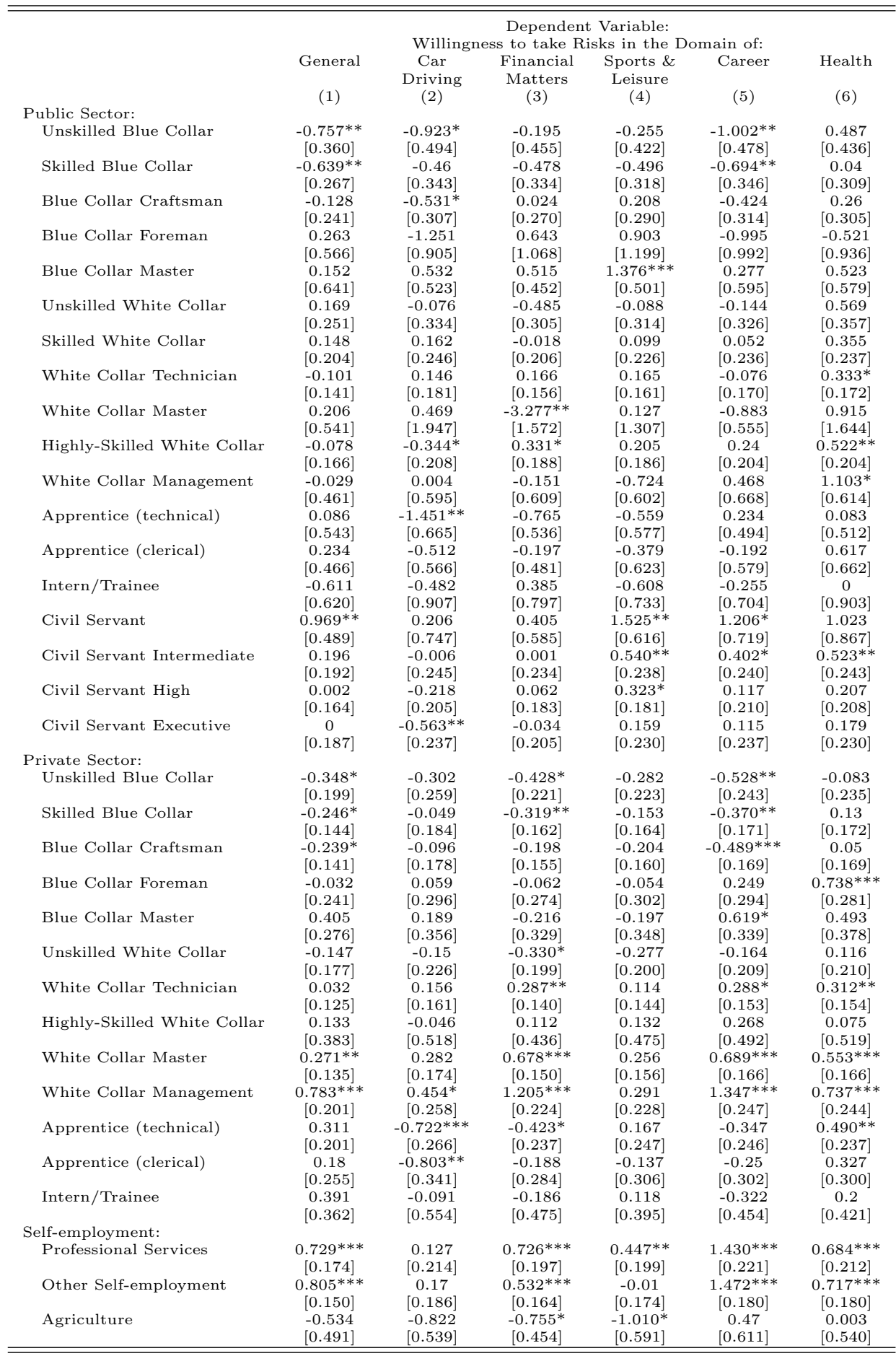


Table A.1: continued: Determinants of Risk Attitudes

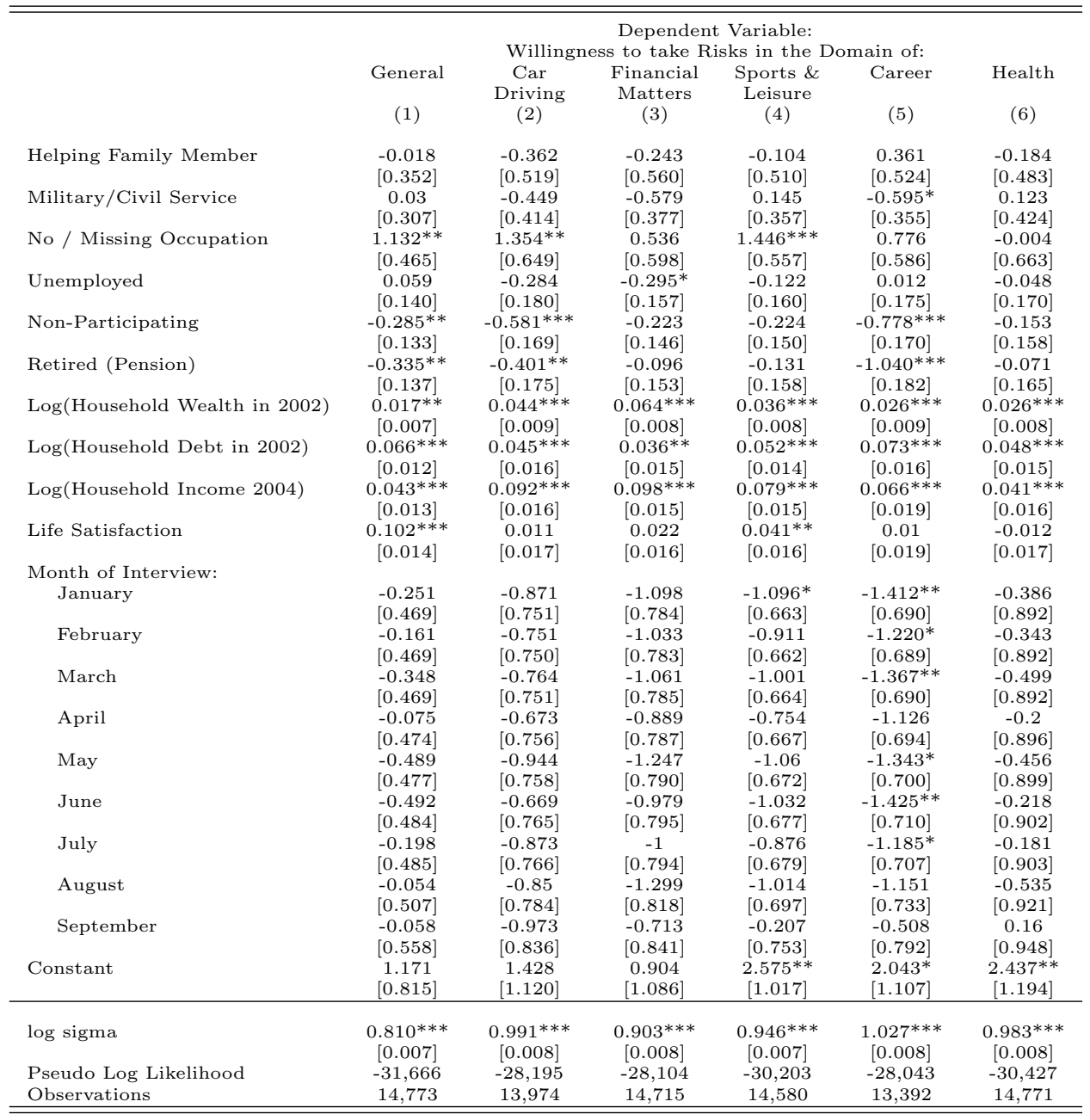

Interval regression coefficient estimates. The dependent variable is a measure for risk attitudes in the respective domain measured on a scale from 0 to 10 , where 0 indicates "not at all willing to take risks" and 10 indicates "very willing to take risks". The Abitur exam is completed at the end of university-track high-schools in Germany; passing the exam is a pre-requisite for attending university or a technical college (we include Fachabitur, the exam for technical college, in the indicator for Abitur.) Information on religion is taken from the 2003 wave. The omitted category is Protestant. The category "No religion" includes those who are not officially affiliated with any type of church. Wealth and income controls are in logs. Information about individual wealth is taken from the 2002 wave of the SOEP, which contains detailed information on different assets and property values, see Schäfer and Schupp (2006) for details. Household wealth is constructed by summing the wealth information of all individuals in the household, and is treated as missing if the wealth information is missing for at least one member of the household. An exception is the case where the individual with missing wealth participated in the survey for the first time in 2004, and is younger than 20 years of age; in this case the missing value for the (teenage) individual's wealth is assumed to indicate zero wealth. Results are qualitatively unchanged if we do not make this assumption. Logged absolute values of negative wealth are added as a separate control variable in the respective specifications. Wealth and income controls are in logs. Logged absolute values of negative wealth are added as separate control. The income data for 2004 are based on answers to questions about current gross monthly income sources at the time of the interview. We also used the net monthly income measure that is available as a generated variable in the SOEP; the results (not reported here) are essentially the same. Robust standard errors in brackets allow for clustering at the household level; ***,**,* indicate significance at 1-, 5-, and 10-percent level, respectively. 